\title{
A comparative analysis of serum lipid profile between normotensive and hypertensive pregnant women
}

\author{
Sridhara S. K.* \\ Department of Obstetrics and Gynecology, Hassan Institute of Medical Sciences, Hassan, Karnataka, India \\ Received: 12 March 2019 \\ Accepted: 12 April 2019 \\ *Correspondence: \\ Dr. Sridhara S. K., \\ E-mail: sksridhara1@gmail.com \\ Copyright: (c) the author(s), publisher and licensee Medip Academy. This is an open-access article distributed under \\ the terms of the Creative Commons Attribution Non-Commercial License, which permits unrestricted non-commercial \\ use, distribution, and reproduction in any medium, provided the original work is properly cited.
}

\begin{abstract}
Background: The pregnancy results in the development of the placenta which is characterized by the hormonal changes in the women body, which results in the alteration of lipid profile, diabetic state of the pregnant mothers and many others. Objective of this study was to compare the of serum lipid profile between normotensive and hypertensive pregnant women.

Methods: A hospital based cross sectional study was conducted by the department of OBG, Hassan Institute of Medical Sciences, Hassan from July 2018 to December 2018. A total of 6 months the study was conducted. A total of 50 pregnant mothers who were more than 20 weeks of gestation and suffering from Preeclampsia were include in the study group and 50 Pregnant mothers who were more than 20 weeks of gestation and normotensive were included in the controls.

Results: Majority of the study subjects in both the groups were less than 25 years of age. The mean age of mothers in study group was 23.19 years and 24.19 years in the control group. The mean HDL level was more among the normotensive group than the pre eclamptic group and the $\mathrm{p}$ value was found to be statistically insignificant. The VLDL, LDL and triglyceride level was more in the pre eclamptic group than the normotensive group and the association was also found to be statistically significant.

Conclusions: Hormonal changes in pregnancy results in physiological Hyperlipidemia, in conditions like preeclampsia triglyceride are elevated more than the normal rise seen in normal pregnancy. Increased lipid profile with raised TG, VLDL, LDL levels leads to the development of Preeclampsia by increasing the oxidative stress and the endothelial dysfunction.
\end{abstract}

Keywords: Endothelial dysfunction, Lipid Profile, PIH, Preeclampsia

\section{INTRODUCTION}

Pregnancy is a condition which is associated with lot of changes in the antomy, Physiology and biochemistry of the women body.

The pregnancy results in the development of the placenta which is characterized by the hormonal changes in the women body, which results in the alteration of lipid profile, diabetic state of the preganant mothers and many others.
Gestational hypertension which was formerly called Pregnancy Induced Hypertension (PIH) is defined as blood pressure of $\geq 140 / 90 \mathrm{~mm}$ of $\mathrm{Hg}$ noted for the first time during pregnancy on $\geq 2$ occasions at least 6 hours apart, after 20 weeks of gestation without associated proteinuria. Blood pressure returns to normal within 12 weeks of post-partum. ${ }^{1}$

When gestational hypertension is associated with proteinuria of $\geq 300 \mathrm{mg} / 24$ hours or $\geq 1+$ by dipstick 
method in a random urine sample, is known as preeclampsia. ${ }^{1}$

The lipid profile of the pregnant mothers depends directly on the levels of the blood pressure.

The incidence of gestational hypertension is approximately $15 \%$ of the total pregnancies while the preeclampsia is seen in around $5-6 \%$ of the total pregnancies. The incidence of the preeclampsia is seen 4 times more often among primigravida when compared to multiparous women. ${ }^{2,3}$

Preeclampsia is also one of the leading cause of the maternal and fetal mortality and morbidity. ${ }^{4}$ The etiopathogensis of the preeclampsia still remains obscure and its poorly understood.

The preeclampsia results in a complex pathophysiological state where there will be alteration in the regulatory systems of inflammation and the endothelial dysfunction which are often altered beyond the normal physiological limits of the pregnancy state.

The spectrum of endothelial changes is provoked by multiple circulating factors including altered lipoproteins. Endothelial dysfunction explains many of symptoms of preeclampsia including proteinuria. 5,6

Even in normal pregnancy there is increase in plasma lipid seen, but in normal pregnancy it is not atherogenic, may be physiological, due to hormonal control. Whenever this mechanism of adjusting physiologic hyperlipidemia is altered that lead to complications in pregnancy. Even before, some studies evaluated lipid profile in preeclampsia and relationship between lipid concentration (Serum triglycerides) and severity of preeclampsia is evaluated..$^{7-9}$

Normal human pregnancy results in pronounced physiologic hyperlipidemia involving a gestational rise in blood triglyceride and cholesterol. Women with Preeclampsia display additional alterations in blood lipids, which represent a disorder in lipid and lipoprotein metabolism. So, in pregnancy if serum lipid profiles are estimated it helps to identify high risk cases prone for preeclampsia.

The objective of this study was to compare the of serum lipid profile between normotensive and hypertensive pregnant women.

\section{METHODS}

A hospital based cross sectional study was conducted by the department of obstetrics and gynecology, Hassan Institute of Medical Sciences, Hassan from July 2018 to December 2018. A total of 6 months the study was conducted.
A total of 50 pregnant mothers who were more than 20 weeks of gestation and suffering from Preeclampsia were include in the study group and 50 pregnant mothers who were more than 20 weeks of gestation and normotensive were included in the controls.

\section{Inclusion criteria}

- $\quad$ The all pregnant women with pre-eclampsia and $>20$ weeks of gestation.

\section{Exclusion criteria}

- Chronic hypertensive and preeclampsia < 20 weeks of gestation, renal disease, diabetics, hepatic dysfunction, and patients with known dyslipidemia.

\section{Statistical analysis}

The data was entered in excel sheet and analyzed using SPSS V 21. The continuous variables were expressed as Mean and SD, Proportions as Percentage. Chi-square test and $\mathrm{T}$ test was used to check for the association. $\mathrm{O}$ value less than 0.05 was considered statistically significant.

\section{RESULTS}

A total 100 study subjects were analyzed.

Majority of the study subjects in both the groups were less than 25 years of age. The mean age of mothers in study group was 23.19 years and 24.19 years in the control group. The age was found to be not significantly associated with the pre-eclampsia and normotensive mothers. Majority of the mothers in the study group were primigravida when compared with the study group and gravid was also found to be statistically insignificant (Table 1). The BMI was found to be almost similar in both the group and the association of BMI was also statistically insignificant. The mean Gestational Age was 35.87 months in the study group and 35.29 months in the control group.

The blood pressure reading of systolic, diastolic, and Mean Arterial Blood Pressure was found to be much higher in the study group when compared with the control group and the differences of all the variables was also found to be statistically significant (Table 2).

The lipid profile was estimated in both the groups and the mean value of each variable was estimated. The mean HDL level was more among the normotensive group than the pre eclamptic group and the $p$ value was found to be statistically insignificant. The VLDL, LDL and triglyceride level was more in the pre eclamptic group than the normotensive group and the association was also found to be statistically significant. Even though the total cholesterol levels were more in the preeclamptic group the association of total cholesterol was found to be statistically insignificant (Table 3). 
Table 1: Association between socio-demographic factors and Pre -eclampsia among study subjects.

\begin{tabular}{|c|c|c|c|c|}
\hline Characteristics & $\begin{array}{l}\text { Pre-ecliptic Patients } \mathbf{n}=\mathbf{5 0} \\
\text { free }(\%)\end{array}$ & $\begin{array}{l}\text { Normotensive } \mathbf{n}=\mathbf{5 0} \\
\text { free }(\%)\end{array}$ & Chi-Square test & P-Value \\
\hline \multicolumn{5}{|l|}{ Age (years) } \\
\hline$<20$ & $11(22)$ & $15(30)$ & & \\
\hline $20-24$ & $19(38)$ & $12(24)$ & & \\
\hline $25-29$ & $6(12)$ & $8(16)$ & 2.5406 & 0.637 \\
\hline $30-34$ & $8(16)$ & $9(18)$ & & \\
\hline \multirow[t]{2}{*}{$35-39$} & $6(12)$ & $6(12)$ & & \\
\hline & & & Student t-test & \\
\hline Mean age (years) & $23.19 \pm 6.5$ & $24.19 \pm 6.35$ & -0.71 & 0.641 \\
\hline Parity & & & Chi-Square test & \\
\hline Prim gravidae & $32(65)$ & $24(48)$ & & \\
\hline $1-4$ & $5(10)$ & $16(37)$ & $X^{2}=8.168$ & $>0.05$ \\
\hline$\geq 5$ & $13(25)$ & $7(15)$ & & \\
\hline
\end{tabular}

Table 2: Association between clinical characteristics and pre-eclampsia among study subjects.

\begin{tabular}{|c|c|c|c|c|}
\hline Characteristics & $\begin{array}{l}\text { Pre-ecliptic patients } \\
n=50 \text { free }(\%)\end{array}$ & $\begin{array}{l}\text { Normotensive } \\
\mathbf{n}=\mathbf{5 0} \text { free }(\%)\end{array}$ & Student t-test & P-Value \\
\hline Mean body mass index $\left(\mathrm{Kg} / \mathrm{m}^{2}\right)$ & $24.87 \pm 1.77$ & $24.35 \pm 6.18$ & 1.87 & 0.064 \\
\hline \multicolumn{5}{|l|}{ Gestational age (weeks) } \\
\hline $20-26$ & $6(12)$ & $4(8)$ & & \\
\hline$\geq 27$ & $44(88)$ & $46(92)$ & & \\
\hline Mean gestational age & $35.87 \pm 2.58$ & $35.29 \pm 2.00$ & 1.50 & 0.136 \\
\hline $\mathrm{SBP}(\mathrm{mmHg})$ & $164.4 \pm 21.4$ & $112.2 \pm 12.1$ & 19.96 & $<0.001$ \\
\hline $\mathrm{DBP}(\mathrm{mmHg})$ & $107.6 \pm 14.3$ & $69.45 \pm 7.22$ & 21.45 & $<0.001$ \\
\hline $\mathrm{MABP}(\mathrm{mmHg})$ & $126.7 \pm 16.40$ & $83.29 \pm 8.12$ & 23.43 & $<0.001$ \\
\hline
\end{tabular}

Table 3: Association between mean lipid levels and pre-eclampsia among study subjects.

\begin{tabular}{|lllll|}
\hline Parameters & Pre-ecliptic $(\mathrm{n}=50)$ & Normotensive $(\mathrm{n}=50)$ & Student t-test & P-value \\
\hline HDL $(\mathrm{mmol} / \mathrm{L})$ & $1.25 \pm 0.36$ & $1.47 \pm 0.41$ & 2.21 & 0.023 \\
\hline VLDL $(\mathrm{mmol} / \mathrm{L})$ & $0.51 \pm 0.29$ & $0.39 \pm 0.12$ & 5.75 & $<0.001$ \\
\hline LDL $(\mathrm{mmol} / \mathrm{L})$ & $3.70 \pm 1.06$ & $2.77 \pm 0.95$ & 5.76 & $<0.001$ \\
\hline Total cholesterol $(\mathrm{mmol} / \mathrm{L})$ & $6.73 \pm 1.65$ & $6.12 \pm 1.28$ & 1.38 & 0.160 \\
\hline Triglyceride $(\mathrm{mmol} / \mathrm{L})$ & $2.76 \pm 1.26$ & $1.86 \pm 0.57$ & 5.77 & $<0.001$ \\
\hline
\end{tabular}

Table 4: Pearson's correlation co-efficient examining association between lipid levels and pre-eclampsia.

\begin{tabular}{|ll|l|}
\hline Lipid fractions & $\begin{array}{l}\text { Pearson's correlation } \\
\text { co-efficient }\end{array}$ & $\begin{array}{l}\text { P- } \\
\text { value }\end{array}$ \\
\hline HDL (mmol/L) & -0.012 & 0.931 \\
\hline VLDL (mmol/L) & 0.288 & 0.013 \\
\hline LDL(mmol/L) & 0.060 & 0.650 \\
\hline $\begin{array}{l}\text { Total cholesterol } \\
\text { (mmol/L) }\end{array}$ & 0.239 & 0.048 \\
\hline Triglyceride (mmol/L) & 0.280 & 0.016 \\
\hline
\end{tabular}

The association of the serum lipid profile was correlated with the preeclamptic condition of the patients and it was found that all the lipid profiles like VLDL, LDL, Triglyceride, Total Cholesterol levels were having positive co relation and HDL had negative correlation in our study (Table 4).

\section{DISCUSSION}

In the present study we did a comparative study to check the serum lipid profile among the preeclmptic and normotensive groups. The preeclmptic group was the study group and the normotensive group was the control group.

Various articles and literatures have established that the with increased pregnancy age the lipid profile also increases gradually among all the pregnant women's. ${ }^{9,10}$ Similarly in our present study the serum levels of TG, VLDL, LDL and Total Cholesterol levels were 
significantly increased in the study group than the control group, whereas $\mathrm{HDH}$ was seen vice versa.

The preeclmptic state is significantly associated with hypertriglyceridemia. The principal modulator of hypertriglyceridemia is estrogen which is also associated with hyperoestrogenaemia during pregnancy. Endothelial dysfunction is the most important event in the pathogenesis of hypertension during pregnancy and abnormal levels of lipid profile play their critical role in the induction of endothelial dysfunction. ${ }^{11-13}$

In our study the mean serum triglyceride levels were higher in the study group than the control group, similar findings were also seen in the studies done by Commaracammy A et al, Torum Clausen et al, Ware Jauregui $\mathrm{S}$ et al, and Mohanty $\mathrm{S}$ et al. ${ }^{14-17}$ This changes seen in the preeclmaptic patients is due to increased hepatic lipase activity and decrease in lipoprotein lipase activity and also there will be delay in the uptake of triglyceride to the liver among the pre eclamaptic pregnancies.

Similarly, the serum total cholesterol levels were also seen more in the preeclmptic group than the normotensive group in our study. In the studies done by Howlader Z et al, Ware Jauregui S et al, and Mohanty S et al, similar findings were obtained. ${ }^{16-18}$ the increased insulin resistance in the pregnancy state and the reverse transport of cholesterol to the liver due to decreased HDL level was the reason for the increased total cholesterol levels among such patients.

The findings of the increased LDL levels among the preeclampsia patients in our study was also observed in the studies done by Negrato Carlos A et al, Commaracammy A et al, and Clausen Tet al. ${ }^{14,15,19}$

The HDL cholesterol findings was contrasting when compared to other lipid profile components where HDL levels were less among the Preeclamptic patients than the normotensive and the correlation of HDL Lipoprotein was also found to be negative. Reduction in HDL cholesterol is due to hypertriglyceridemia, which forms TG rich HDL particles through CETP mediated exchange with TG rich VLDL particles. Hepatic lipase rapidly catabolizes TG rich HDL particles and decreasing it concentration. In the study done by Carlos A et al, Warejauregui S et al, and Commaracammy A et al, were co relating to the findings of our study. ${ }^{14,16,19}$

\section{CONCLUSION}

Hormonal changes in pregnancy results in physiological hyperlipidemia, in conditions like pre-eclampsia triglyceride are elevated more than the normal rise seen in normal pregnancy. Increased lipid profile with raised TG, VLDL, LDL levels leads to the development of Preeclampsia by increasing the oxidative stress and the endothelial dysfunction. By detecting lipid profile changes in the pregnancy at the early stage will be helpful in treating and prevention and also to slow down the progression of the disease by proper medication and life style modifications.

\section{Funding: No funding sources Conflict of interest: None declared}

Ethical approval: The study was approved by the Institutional Ethics Committee

\section{REFERENCES}

1. Gary CF, Levena KJ, Bloom SL, Hauth JC, Gilstrap $\mathrm{L}$, Wenstrom KD. Hypertensive disorders in pregnancy. In: Williams obstetrics. $22^{\text {nd }}$ ed., New York; McGraw Hill. 2005:761-808.

2. Bansal S. Hypertension in pregnancy. In: Desai P, Malhotra N, Shah D. Principles and Practice of Obstetrics and Gynecology for Post Graduates. 3rd ed., New Delhi; Jaypee Brothers Medical Publishers (P) Ltd. 2008;100-7.

3. Dutta DC. Hypertensive disorders in pregnancy. In: Dutta DC. Text Book of Obstetrics. 3rd ed., Calcutta; New Central Book Agency (P) Ltd. 1994;230-6.

4. Carl A. Hubel. Oxidative Stress in the Pathogenesia of Preeclampsia. Exp Biol Med. 1999:222(3):222-3.

5. Adiga U, D'souza V, Kamath A, Mangalore N. Antioxidant activity and lipid perxidation in preeclampsia. J Chin Assoc. 2007:70(10):435-8.

6. Cekman MB, Erbagci AB, Balat A, Puman C, Maral $\mathrm{H}$, Ergen $\mathrm{K}$, et al. Plasma lipid and lipoprotein concentrations in pregnancy induced hypertension. Clin Biochem. 2003:36(7):575-8.

7. Jayanta D, Mukhopadhya AK, Saha PK. Study of serum lipid profile in pregnancy induced by hypertension. Indian $\mathrm{J}$ Clin Biochem. 2006;21(2):165-8.

8. Sibai BM, El-Nazer A, Gonzalez-Ruiz A. A severe preeclampsiaeclampsia in young primigravid women: subsequent pregnancy outcome and remote prognosis, Am J Obstet Gynecol. 1986;155:1011.

9. Potter JM, Nestel PJ. The hyperlipidemia of pregnancy in normal and complicated pregnancies. Am J Obstet Gynecol. 1979;133:165-70.

10. Salameh WA, Mastrogiannis DS. Maternal hyperlipidemia in pregnancy. Clin Obstet Gynecol. 1994;37:66-77.

11. Sattar N, Bendomir A, Berry C, Shepherd J, Greer IA, et al. Lipoprotein subfraction concentrations in preeclampsia: pathogenic parallels to atherosclerosis. Obstet Gynecol. 1997;89:403-8.

12. Ray JG, Diamond P, Singh G, Bell CM. Brief overview of maternal triglycerides as a risk factor for pre-eclampsia. BJOG. 2006;113:379-86.

13. Aziz R, Mahboob T. Pre-eclampsia and lipid profile. Pak J Med Sci. 2007;23:751-4.

14. Commaracamy A, Honest H Papaioannon S, Gee H, Khanks, Aspirin for prevention of preeclampsia in women with historical risk factors: a systematic review. Obstet Gynaecol. 2003:101:1319-32. 
15. Clausen T, Djurovic S, Henriksen T. Dyslipidemia in early second trimester is mainly a feature of women with early onset pre-eclampsia. BJOG. 2001;108:1081-7.

16. Ware-Jauregui S, Sanchez SE, Zhang C. Plasma lipid concentrations in pre-eclamptic and normotensive Peruvian women. Int J Gynecol Obstet. 1999;67(3):147-55.

17. Mohanty S, Nayak N, Nanda N, Rao P. Serum lipids and malondialdehyde levels in primiparous patients with pregnancy induced hypertension. Indian J Clin Biochem. 2006;21(1):189-92.

18. Howlader Z, Kabir Y, Khan T, Islam R, Begum F, Huffman F. Plasma lipid profile, lipid peroxidation and antioxidant status in preeclamptic and uncomplicated pregnancies in Bangladesh. J Med Sci. 2007;7(8):1276-82.

19. Negrato CA, Jovanovic L, Tambascia MA. Association between insulin resistance, glucose intolerance and hypertension in pregnancy. Metabol Synd Rel Disord. 2009;7(1):53-9.

Cite this article as: Sridhara SK. A comparative analysis of serum lipid profile between normotensive and hypertensive pregnant women. Int J Reprod Contracept Obstet Gynecol 2019;8:2060-4. 